\title{
A Community-Based "Street Team" Tobacco Cessation Intervention by and for Youth and Young Adults
}

\author{
Anne Saw ${ }^{1}\left[\right.$ Crystal N. Steltenpohl $^{2} \cdot$ Kimberly Bankston-Lee $^{3} \cdot$ Elisa K. Tong $^{4}$
}

(C) Springer Science+Business Media, LLC 2017

\begin{abstract}
Most tobacco users initiate use as youth or young adults. To promote tobacco cessation for this group and encourage non-users' engagement in tobacco control efforts, a community-based organization developed a "Street Team" brief outreach intervention that enlisted youth and young adults to encourage their peers to stop tobacco use through a brief intervention. Street Team members provided education, a Quit Kit, and referrals to cessation resources at a total of 27 community events over a four-year period. Tobacco users $(n=279)$ completed assessments of tobacco use, quit intention, and quit self-efficacy at baseline. Self-reports of cessation outcomes including past week abstinence were assessed 1-, 3-, and 6-months post-intervention. Perceptions of the intervention were gathered from Street Team members $(n=28)$ and intervention participants post-intervention. $T$-tests and $\chi^{2}$-tests were used to compare those who completed at least one follow-up assessment to those lost to follow-up. Time effects were analyzed using fixed effect models. Missing = using analyses indicate 16.1, 18.6, and $12.5 \%$ 7-day quit rate at 1-, 3-, and 6-months follow-up. Feedback from intervention participants indicate the intervention was acceptable and that discussions with Street Team members
\end{abstract}

Anne Saw

asaw@depaul.edu

1 Department of Psychology, DePaul University, 2219 N. Kenmore Ave., Byrne Hall, Room 560, Chicago, IL 60614, USA

2 Department of Psychology, Southern Indiana University, Evansville, IN, USA

3 Breathe California of Sacramento-Emigrant Trails, Sacramento, CA, USA

4 Department of Internal Medicine, University of California Davis, Davis, CA, USA and provision of quit kits motivated tobacco users to consider quitting. All Street Team members responded positively to their participation in the intervention. This Street Team approach for youth and young adults is promising as an effective approach to the promotion of tobacco cessation among users and engagement and empowerment in tobacco control efforts among non-users.

Keywords Tobacco cessation interventions · Peer health advisors · Motivational enhancement $\cdot$ Youth $\cdot$ Young adults

\section{Introduction}

The vast majority of tobacco users initiate use before the age of 26 [1]. $24.4 \%$ of high school students and $16.7 \%$ of young adults aged 18-24 currently smoke [2, 3]. High school-aged youth and young adults are interested in quitting $[4,5]$, yet, they underutilize available cessation resources compared to adults $[6,7]$.

Interventions targeting youth and young adults that utilize peers as trained helpers who understand social influences on teens may improve reach and effectiveness since many youth and young adults may not seek traditional avenues to receive cessation interventions $[8,9]$. Lay health advisors or influencers have been utilized for tobacco cessation interventions with a variety of tobacco users, such as with White Greek-life college students [10], young Black women [11], and immigrant Vietnamese American men [12]. Most of these interventions involve repeated, prolonged contact between tobacco users and their peers.

In response to the perceived need for effective tobacco cessation interventions targeting youth and young adults in their community, in 2005, the Sacramento Taking 
Action against Nicotine Dependence (hereafter referred to as STAND), a component of a larger community-based organization in Sacramento, California called Breathe California of Sacramento-Emigrant Trails, developed a brief peer outreach tobacco cessation program, the "Street Team" intervention. The objectives of the Street Team intervention were twofold. First, the organization aimed to recruit and train "Street Team members"-high school and college students who delivered the cessation intervention to tobacco users. The purpose of this objective was to equip youth and young adults with knowledge and skills to feel empowered to promote tobacco cessation and actively counter tobacco industry's marketing efforts. Second, the program aimed to promote tobacco cessation among youth and young adults through the delivery of a brief tobacco cessation intervention with motivational enhancement and educational components. This paper describes this program and presents findings of Street Team members and tobacco users who participated in the intervention during a four-year project period from 2005 to 2008.

\section{Method}

\section{Overview of Program}

The STAND program provided brief cessation counseling to youth and young adults delivered by high school and college students who served as Street Team members. Street Team members outreached to youth and young adults at community events, such as festivals and sports games, on high school and college campuses, and in other public places, such as plazas. To attract young tobacco users to participate in the intervention, Street Team members set up booths with educational games that included prizes such as Frisbees, key chains, and drawstring bags. If the tobacco user expressed interest in tobacco cessation, informed consent was obtained. Street Team members then delivered a brief (5-10 min) intervention that included education about tobacco use and cessation, motivational enhancement techniques, provision of "quit kits," and referral to cessation resources including the state quitline. The intervention was delivered at a total of 27 Sacramento community events over a four-year period. 2-10 $(M=6)$ Street Team members provided the intervention to $0-25$ $(\mathrm{M}=10.3)$ tobacco users at each community event. Intervention participants received follow-up call assessments from Street Team members at one, three, and six months after initial face-to-face contact. Analyses of data for the current study were approved by the University of California, Davis Institutional Review Board.

\section{Street Team Member Recruitment and Training}

The organization recruited local youth (ages 15-17) and young adults (ages 18-24) to form a Street Team trained on peer cessation and tobacco prevention. Youth and young adults were recruited from local high schools and colleges. The organization collaborated with schools to provide course credit or community service hours in exchange for participation. Individuals interested in joining the Street Team completed an application and interview before they joined the program and signed voluntary contracts committing to participate for at least one academic quarter. Street Team members received training by STAND staff on the history of the tobacco industry's marketing to young people, tobacco use and dependence, motivational enhancement techniques based on the work of Miller and Rollnick [13], and issues pertinent to youth and young adult smoking, such as social smoking. Training lasted 1.5 days and included lectures, discussions, and roleplays. Street Team members received small incentives ( $\$ 5-\$ 40$ value) that increased based on level of participation in trainings, meetings, and outreach events. Incentives included concert tickets and gift cards.

\section{Cessation Intervention}

The cessation intervention delivered by Street Team members included motivational enhancement techniques, education about tobacco use and cessation, provision of a Quit Kit, and referral to cessation resources including the California Smokers' Helpline. Oral consent was obtained from tobacco users prior to delivery of the intervention. The intervention lasted 5-10 min, during which Street Team members would engage with tobacco users one-on-one using motivational enhancement techniques. Afterwards, the intervention participant was asked to complete a contact form and baseline surveys. Each intervention participant was given a quit kit ( $\$ 8$ value) consisting of a water bottle, an intervention booklet on tobacco cessation developed by STAND that explained how to quit using the tools in the kit, a list of local cessation programs, a card with the state quitline's phone numbers, a pen, a cost of smoking calculator, a stress stick, rubber bands, honey sticks, cinnamon flavored toothpicks, gum, mints, candy, and sunflower seeds.

\section{Evaluation of Street Team member Opinions}

Street Team members completed online surveys consisting of Likert-type, multiple choice, and open-ended questions twice per year in the first year of the project and annually thereafter. Members were asked about their length of time with the project and their weekly time commitment. They were also asked what their highlights for the year, what they enjoyed doing the least, what they enjoyed doing the 
most, their opinions of the events in which STAND participated, what the most beneficial resource was, and what other resources with which they could have provided. Members were also asked for their opinions on STAND as a whole, the trainings, the incentive program, and communication processes. Finally, they were asked if they felt their experiences would help them personally or professionally, how the Street Team could help with building leadership skills, and their opinions on the effect Street Team has had on their personal growth.

\section{Evaluation of Intervention Participants}

Intervention participants completed a demographic form and baseline survey consisting of Likert-type, multiple choice, and open-ended questions about their tobacco use (type, brands, frequency, length of use), self-efficacy for quitting, and past quit experiences. Follow-up surveys included questions about current use status, days since last use (if currently abstained), tobacco use (type, brands, frequency, length of use), stage of readiness to quit, and perceived effectiveness of the intervention components (i.e., quit kit, conversation with Street Team member). Street team members and/or paid program staff attempted three telephone follow-up assessments with intervention participants who provided contact information. The first follow-up call was conducted 4-8 weeks after face-to-face contact; the second call was conducted 12-16 weeks after face-to-face contact. The third and final call was conducted 6-7 months after face-to-face contact. Intervention participants received a $\$ 15$ gift card for each follow-up completed.

\section{Analysis}

Descriptive statistics were reported for demographics, perceptions of the program, and intervention tobacco use variables. 7-day point prevalence was the primary tobacco use outcome of interest; this was measured calculating self-reported 7-day abstinence among respondents at each follow-up and also by using conservative imputation where non-respondents at time point were assumed to still be smoking (i.e., missing $=$ smoking) [14]. $T$-tests and $\chi^{2}$-tests were used to compare those who completed at least one follow-up assessment to those lost to follow-up. Time effects were analyzed using fixed effect models.

\section{Results}

\section{Description of Street Team Members and Intervention Participants}

In total, 28 Street Team members participated in the program during the 4 years of the program. In 2005-2006, 8 youth or young adults participated, ranging in age from 15 to 22 with a median age of 16 ( 7 female, 1 male). Demographic data were not collected in 2006-2007. In 2007-2008, 14 youth or young adults participated, ranging in age from 16 to 24 (median age $=17$ ). Of these 14 members, 4 were male, 8 were female, and 2 did not report their gender. Table 1 describes characteristics of the intervention participants $(N=279)$. Both samples comprised youth and young adults from the Sacramento, California area. Racial/ethnic identification of Street Team members and intervention participants were not collected.

Of the intervention participants, $50.2 \%$ were female and $77.6 \%$ were under age 25 , with the majority (65.6\%) between the ages of $18-25.93 .5 \%$ of participants reported smoking cigarettes; other tobacco products used included smokeless tobacco and hookah. Average length of time using tobacco products was nearly 7 years (range of 2 months -4 years). Mean self-efficacy to quit pre-intervention was 4.05 $(S D=0.90$, range $=1-5)$, indicating they "somewhat" believed they could quit. $82.4 \%$ of participants reported at least one past quit attempt.

\section{Recruitment and Retention}

8-15 Street Team members participated in the program each academic year. $88.9 \%$ of members participated at least two consecutive academic quarters.

279 tobacco users participated in the intervention. Figure 1 shows the retention of intervention participants for follow-up assessments post-intervention. $42.3 \%$ of participants who consented to follow-up participated in the 1-month follow-up assessment. $40.8 \%$ participated in the 3-month follow-up assessment. $27.2 \%$ participated in the 6-month follow-up assessment. Those who responded to at least one follow-up assessment were significantly younger (21.72 vs. 23.84 years, $\mathrm{t}(271)=2.645, \mathrm{p}=.009)$ and more likely to be female $\left(\chi^{2}(1, \mathrm{~N}=279)=6.04, \mathrm{p}=.014\right)$, but did not differ on self-efficacy to quit, having made a previous quit attempt, or length of tobacco use.

\section{Intervention Participant Outcomes}

Table 2 displays intervention participants' tobacco use outcomes at each of three follow-ups. Missing = smoking 7-day point prevalence was $16.1,18.6$, and $12.5 \%$ at one-, three-, and six-month follow-ups respectively. Among respondents 
Table 1 Demographic and baseline tobacco use characteristics of intervention participants $(N=279)$

\begin{tabular}{lrr}
\hline Variable & $\mathrm{n}(\%)$ & $\mathrm{M}(\mathrm{SD})$ \\
\hline Gender & $139(49.8)$ & \\
Male & $140(50.2)$ & $22.69(6.68)$ \\
Female & & \\
Age (years) & $36(13.3)$ & \\
$12-17$ & $180(66.0)$ \\
$18-25$ & $41(15.1)$ & \\
$26-35$ & $16(5.6)$ & \\
$36-54$ & & \\
Types of tobacco used & $261(93.5)$ \\
Cigarettes & $9(3.2)$ \\
Smokeless tobacco & $21(7.5)$ \\
Other (e.g. cigars, hookah, marijuana, etc.) & & \\
Length of time participant has used tobacco, years & $49(17.6)$ \\
Previous quit attempt methods & $160(57.3)$ \\
Never tried to quit before & $11(3.9)$ \\
Cold turkey & $52(18.6)$ \\
Support group & $44(15.8)$ \\
Change behavior & $34(12.2)$ \\
Nicotine patch & $4(1.4)$ \\
Nicotine gum & $7(2.5)$ & \\
Nicotine spray & $24(8.6)$ & \\
Medication & & \\
Other (e.g. pregnancy, hypnosis, jail, chewing gum, etc.) & \\
Self-efficacy to quit & & \\
\hline
\end{tabular}

Self-efficacy to quit measured on a 5-point scale from "not at all" to "very much" who self-reported abstinence at any follow-up, the methods cited for assisting in cessation were: the Quit Kit (69.5\%); friend/family support (46.3\%); nicotine replacement therapy (29.3\%); quit smoking programs, support groups, and the quitline (each $4.9 \%$ ). Among those still using tobacco, the majority reported reduction in use since the intervention at each follow-up, 86.2, 92.2, and 75\% respectively. Current users' mean self-efficacy to quit (i.e., "Do you believe you can quit smoking?" was 4 ("somewhat") on a 5-point scale ranging from "not at all" to "very much" at each follow-up. Fixed effect model analyses indicated no significant effects of time on self-efficacy to quit, $\left(\mathrm{F}(2,54)=0.59, \mathrm{R}^{2}=0.8376\right)$ or stage of readiness to quit $\left(\mathrm{F}(2,54)=0.40, \mathrm{R}^{2}=0.7173\right)$.

\section{Intervention Participants' Perspectives on Intervention}

On a 5-point scale from $1=$ not useful to $5=$ useful, intervention participants $(n=52)$ rated the discussion part of the intervention $4.08(\mathrm{SD}=0.99)$ at 1 -month follow-up, indicating the intervention was somewhat helpful. Helpfulness of the quit kit was assessed among respondents who self-reported abstinence at follow-up. 96.6, 96.6, and 93.3\% reported that the quit kit was helpful to assist in cessation at the three follow-ups. Items in the quit kits reported by abstainers as most helpful to quitting were gum (12.6\%), trail mix (11.2\%), toothpicks (11.0\%), honey sticks $(10.7 \%)$, and stress balls/sticks (10.2\%). The least reported items were the quitline contact card (1.2\%), coffee stir sticks $(2.6 \%)$, pens $(2.8 \%)$, rubber bands $(3.1 \%)$, and brochures with tips on quitting smoking (3.6\%). Those who reported no current tobacco use were asked what part of the discussion with Street Team members was most helpful. The most frequently cited ways in which the discussion was helpful were: providing strategies for quitting $(22.2 \%)$, information about the financial costs of smoking (15.6\%), and information about smoking and its health harms (13.3\%). Among participants who reported current but reduced use at the first follow-up, the most frequently reported ways in which the quit kit was useful were by providing: oral fixation alternatives (e.g., gum, honey sticks) (91.1\%), information about smoking and cessation $(30.4 \%)$, and more generally, motivation to consider quitting $(10.7 \%)$.

\section{Street Team Members' Perspectives on the Program}

Perspectives on the program were gathered for Street Team members who participated in year 3 of the program $(n=11)$. All 11 Street Team members reported receiving adequate 
Fig. 1 Flow chart of intervention participation

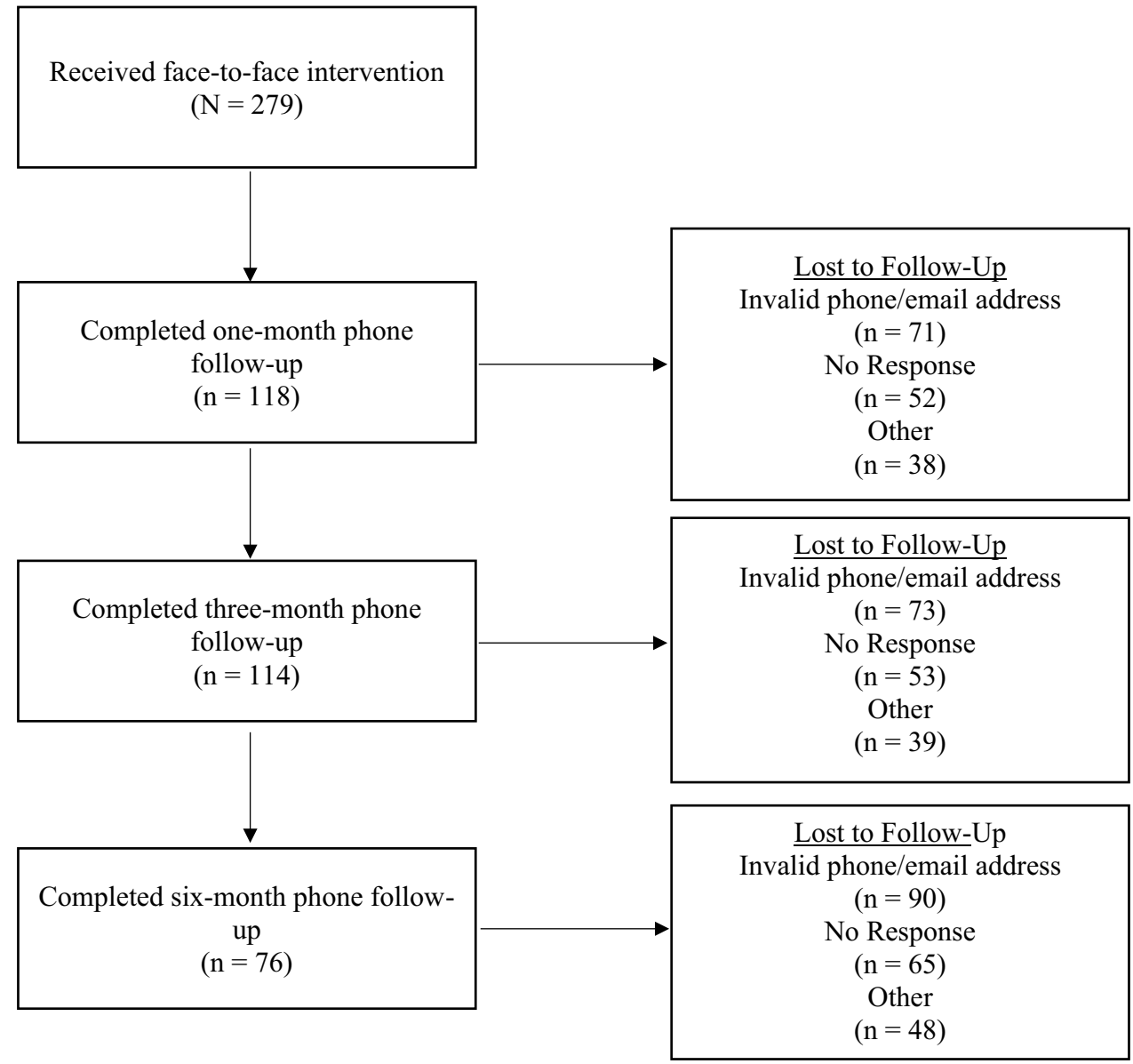

training to provide the intervention and felt their participation in the Street Team was an interesting and valuable experience. All but one agreed that they would recommend the Street Team to their friends as a good volunteer experience. In open-ended responses Street Team members reported feeling that they were an important part of a team, increasing knowledge about tobacco control and cessation, directly impacting others in the community, and gaining applicable leadership skills. For example, one Street Team member wrote:

As a college student, I've experimented with a couple of other internship/volunteer programs and STAND has been the longest one that I've stayed with as well as recommended to others that I know will be beneficial to the team. This may not be for everyone to participate in but volunteering overall in a program like STAND is an invaluable experience. What I've learned and continue to learn goes a long way, including outside of tobacco cessation.

Another Street Team member commented, "the fact that I can campaign against the nicotine corp[oration], get to know fun new people, and help people to live healthier longer lives makes me proud to be a member of the STAND Street Team." In open-ended responses describing what they enjoyed least, $35 \%$ of respondents left the question blank or answered "nothing." The chief complaints about their experiences were: interacting with smokers who did not want to quit or made them feel uncomfortable (15\%), having to complete paperwork on participants $(7.5 \%)$, having to conduct follow-up phone assessments (5\%), and scheduling difficulties $(5 \%)$. Paid staff members also reported difficulties coordinating Street Team members' schedules to be able to participate in community events.

\section{Discussion}

The current study evaluates a community-based intervention to promote tobacco cessation targeting youth and young adults. The program utilized a Street Team approach whereby youth and young adults were trained to engage tobacco users at community events and provide information about health and financial harms of smoking, brief motivational interviewing, strategies for cessation, and quit kits. Conservative missing $=$ smoking analyses indicate modest effectiveness in encouraging tobacco cessation through this program. The majority of intervention participants who did not quit reported reductions in tobacco use. Results suggest the intervention was acceptable to tobacco users and provide 
Table 2 Self-reported tobacco use outcomes of intervention participants $(\mathrm{N}=279)$

\begin{tabular}{|c|c|c|c|c|c|c|}
\hline \multirow[t]{2}{*}{ Variable } & \multicolumn{2}{|c|}{$\begin{array}{l}1 \text { Month Follow-up } \\
(\mathrm{n}=118)\end{array}$} & \multicolumn{2}{|c|}{$\begin{array}{l}3 \text { Month Follow-up } \\
(\mathrm{n}=114)\end{array}$} & \multicolumn{2}{|c|}{$\begin{array}{l}6 \text { Month Follow-up } \\
(\mathrm{n}=76)\end{array}$} \\
\hline & $\mathrm{n}(\%)$ & $\mathrm{M}(\mathrm{SD})$ & $\mathrm{n}(\%)$ & $\mathrm{M}(\mathrm{SD})$ & $\mathrm{n}(\%)$ & $\mathrm{M}(\mathrm{SD})$ \\
\hline \multicolumn{7}{|l|}{ 7-day abstinence } \\
\hline Observed rate & 45 (38.5) & & $52(46.8)$ & & $35(46.7)$ & \\
\hline Missing $=$ smoking rate & $45(16.1)$ & & $52(18.6)$ & & $35(12.5)$ & \\
\hline \# cigarettes/day & & $4.55(4.19)$ & & $4.50(3.90)$ & & $5.15(5.15)$ \\
\hline$<1$ & 0 & & $1(2.0)$ & & $1(3.1)$ & \\
\hline $1-2$ & $21(36.2)$ & & $16(31.4)$ & & $8(25.0)$ & \\
\hline $3-4$ & $20(34.5)$ & & $18(35.3)$ & & $8(25.0)$ & \\
\hline $5-6$ & $4(6.9)$ & & $8(15.7)$ & & $4(12.5)$ & \\
\hline $7-10$ & $11(19.0)$ & & $5(9.8)$ & & $7(21.9)$ & \\
\hline $11-15$ & $1(1.7)$ & & $2(3.9)$ & & $1(3.1)$ & \\
\hline $16-20$ & $1(1.7)$ & & $1(2.0)$ & & $3(9.4)$ & \\
\hline Reduction in use & $50(86.2)$ & & $47(92.2)$ & & $24(75.0)$ & \\
\hline Believe can quit (1-5) & & $4.38(.75)$ & & $4.51(.67)$ & & $4.19(.86)$ \\
\hline \multicolumn{7}{|l|}{ Quit intention } \\
\hline No thoughts & 0 & & 0 & & 0 & \\
\hline Someday & $6(10.3)$ & & $4(7.8)$ & & $4(12.5)$ & \\
\hline Thinking, not ready & $7(12.1)$ & & $7(13.7)$ & & 7 (21.9) & \\
\hline Thinking & $5(8.6)$ & & $3(5.9)$ & & $5(15.6)$ & \\
\hline Trying & $40(69.0)$ & & $37(72.5)$ & & $16(50.0)$ & \\
\hline
\end{tabular}

Observed rates were calculated as the number reporting 7-day abstinence divided by the number of respondents at each follow-up. Missing $=$ smoking rates were calculated as the number reporting 7-day abstinence divided by the total number of participants $(\mathrm{N}=279)$. Self-efficacy to quit measured on a 5-point scale from "not at all" to "very much"

insights on intervention components that are most useful to individuals attempting to quit tobacco use. Furthermore, data from Street Team members who delivered the intervention suggest that the program created opportunities for nonsmoking youth and young adults to feel empowered in tobacco prevention and cessation efforts.

The missing $=$ smoking 7 -day quit rates at 3 - and 6-month follow-up of $18.6 \%$ and $12.5 \%$ were on par with other lightor moderately-intensive brief cessation interventions targeting young adults $[15,16]$. Among college student smokers, Abroms et al. observed a 7-day quit rate of $25 \%$ that was $10.2 \%$ after biochemical verification at 6-month follow-up in an intervention that included a 15-minute in-person counseling session, provision of a quit kit, and follow-up counseling emails. Counselors in this study were trained undergraduates or masters of public health students. In a study of rural, low SES young adult tobacco users, Zanis et al. found that a brief 5-minute advice and motivational interviewing session with a health educator yielded a self-reported 30-day quit rate of $19.6 \%$ at 3-month follow-up. Further research using randomized controlled trials is needed to examine the effectiveness of this Street Team approach.

Study results point to intervention components that were most helpful in encouraging cessation. Open-ended text responses on participant follow-up surveys indicate that the interaction with the Street Team member was helpful for providing strategies for cessation and information about the health and financial consequences of smoking. Among participants who reported quitting, 70\% reported that the Quit Kit aided in their cessation efforts. In particular, participants reported utilizing alternatives to tobacco that they could place in their mouths, such as gum, snacks, and toothpicks, or could keep their hands occupied, such as stress balls. Of note, although the quit kit included information on the state quitline, only one intervention participant reported having used the quitline. In considering what aspects of the intervention could be changed, direct referral to the quitline during face-to-face interactions with tobacco users and in Quit Kit materials could increase engagement with services. Direct referral in the clinic setting has been associated with a 13-time increased likelihood of a tobacco user connecting with a quitline $[17,18]$.

Acceptability of the intervention was also assessed from the perspectives of Street Team members. Although the majority of the feedback was positive, some Street Team members reported uncomfortable interactions with participants as their least favorite aspect of their service. Staff and volunteer Street Team members voiced concerns about scheduling difficulties since all Street Team members were full-time high school or college students. Furthermore, a 
few Street Team members reported not enjoying completing paperwork and/or conducting follow-up calls with intervention participants. These logistic difficulties should not be overlooked in future interventions using peer Street Team members and more training of Street Team members to handle difficult interactions and education on the importance of data collection and follow-up with quitline services may help allay some of these challenges. Overall, Street Team members viewed their experiences very positively, and many returned for multiple quarters of service.

Recruiting youth and young adults with volunteer or school credits was a key feature that enhances potential scalability of this program. In the future, federal work-study programs for students might be investigated as a mechanism for reimbursement of Street Team time, instead of the Street Team's incentive-based structure. This would enable future Street Team members to represent diverse socioeconomic backgrounds, some of whom may come from communities with higher smoking prevalence rates [19]. Now with a National Tobacco-Free Campus Initiative at over 1500 smoke-free colleges to date, this model could potentially recruit students from these colleges to engage in communitybased outreach where they live [20].

There are important limitations of the current study to consider. First, this evaluation is based on a single group design that was meant for real-world implementation. To better understand overall effectiveness and specific components that are most effective, the intervention should be tested in dismantling and randomized controlled trial study designs. Fidelity of the intervention was not measured, so it is unclear how closely Street Team members adhered to established motivational enhancement techniques. Tobacco use outcomes were measured using self-report and assessed with 7-day point prevalence. Biochemical verification is a more accurate assessment of tobacco use as self-report tends to underestimate use [21]. Long term abstinence cannot be ascertained from the current study. Many intervention participants were lost to follow-up. Missing data were addressed in analyses by assuming nonrespondents were still smoking. Although this method is widely used (e.g., [22-24]), this likely is not an accurate estimate of the impact of the intervention on smoking cessation [14]. Moreover, the large proportion of those lost to follow-up suggest that future iterations of this type of approach must consider how best to maintain ongoing contact with intervention participants, such as with text messaging or social media, and perhaps provide greater incentives for completing follow-up assessments. Electronic cigarettes, which were not widely available at the time of the Street Team activities, were not included in this study. The results of the current study cannot be generalized to those of participants in other communities.

Despite these limitations, the current study provides an overview and evaluation of a tobacco cessation intervention developed by a community organization that targeted, through its intervention design and outreach, non-treatment seeking youth and young adults. This type of intervention based in the community (rather than at schools or health clinics) and administered by peers (rather than professionals) should be considered in future cessation efforts with youth and young adult tobacco users given the potential to reach a considered population that, though interested in quitting, may be unwilling or unable to seek traditional avenues of cessation.

Acknowledgements We gratefully acknowledge the contributions of Leslie Snoke Ferreira and Gustavo Torrez, who developed the Street Team intervention and provided feedback on this paper. We also thank Camilla Cummings for her contributions to the data analyses.

Funding This study was funded by County of Sacramento Department of Health and Human Services, Tobacco Litigation Settlement Funds - Tobacco Cessation, Education and Prevention Services; California Tobacco-Related Disease Research Program (\#22BT-0057H).

\section{Compliance with Ethical Standards}

Conflict of interest The authors declare that they have no conflict of interest.

\section{References}

1. US Department of Health and Human Services. (2012). Preventing tobacco use among youth and young adults: A report of the Surgeon General. Atlanta, GA: Centers for Disease Control and Prevention.

2. Centers for Disease Control and Prevention. (2015). Current cigarette smoking among adults-United States, 2005-2014. MMWR, 64, 1233-1240. http://www.cdc.gov/mmwr/preview/ mmwrhtml/mm6444a2.htm?s_cid=mm6444a2_w Retrieved from http://www.cdc.gov/mmwr/preview/mmwrhtml/mm6444a2. htm?s_cid=mm6444a2_w.

3. Centers for Disease Control and Prevention. (2015). Tobacco use among middle and high school students-United States, 2011-2014. MMWR, 64, 381-385. http://www.cdc.gov/mmwr/ preview $/ \mathrm{mmwrhtml} / \mathrm{mm} 6414 \mathrm{a} 3 . \mathrm{htm}$ ?s_cid=mm6414a3 Retrieved from http://www.cdc.gov/mmwr/preview/mmwrhtml/mm6414a3. htm?s_cid=mm6414a3.

4. Centers for Disease Control and Prevention. (2012). Youth Risk Behavior Surveillance-United States, 2011. MMWR Surveillance Summaries, 61, 1-162. http://www.cdc.gov/mmwr/preview/ mmwrhtml/ss6104a1.htm Retrieved from http://www.cdc.gov/ mmwr/preview/mmwrhtml/ss6104a1.htm.

5. Centers for Disease Control and Prevention. (2015). Trends in quit attempts among adult cigarette smokers-United States, 20012013. MMWR, 64, 1129-1135. http://www.cdc.gov/mmwr/preview/mmwrhtml/mm6440a1.htm?s_cid=mm6440a1_w Retrieved from http://www.cdc.gov/mmwr/preview/mmwrhtml/mm6440a1. htm?s_cid=mm6440a1_w.

6. Curry, S. J., Sporer, A. K., Pugach, O., Campbell, R. T., \& Emery, S. (2007). Use of tobacco cessation treatments among young adult smokers: 2005 National Health Interview Survey. American Journal of Public Health, 97, 1464-1469. doi:10.2105/ AJPH.2006.103788. 
7. Hughes, J. R., Cohen, B., \& Callas, P. W. (2009). Treatment seeking for smoking cessation among young adults. Journal of Substance Abuse Treatment, 37, 211-213. doi:10.1016/j. jsat.2008.11.006.

8. Eng, E., Parker, E., \& Harlan, C. (1997). Lay health advisor intervention strategies: A continuum from natural helping to paraprofessional helping. Health Education \& Behavior, 24, 413-417. doi:10.1177/109019819702400402.

9. Eng, E., \& Young, R. (1992). Lay health advisors as community change agents. Family \& Community Health, 15, 24-40.

10. Varvel, S. J., Cronk, N. J., Harris, K. J., \& Scott, A. B. (2010). Adaptation of a lay health advisor model as a recruitment and retention strategy in a clinical trial of college student smokers. Health Promotion Practice, 11, 751-759. doi:10.1177/1524839908325065.

11. Lacey, L., Tukes, S., Manfredi, C., \& Warnecke, R. B. (1991). Use of lay health educators for smoking cessation in a hard-to-reach urban community. Journal of Community Health, 16(5), 269-282.

12. Tsoh, J. Y., Burke, N. J., Gildengorin, G., Wong, C., Le, K., Nguyen, A., ... Nguyen, T. T. (2015). A social network familyfocused intervention to promote smoking cessation in Chinese and Vietnamese American male smokers: A feasibility study. Nicotine \& Tobacco Research, 17, 1029-1038. doi:10.1093/ntr/ntv088.

13. Miller, W. R., \& Rollnick, S. (2002). Motivational interviewing: Preparing people for change (2nd ed). New York, NY: Guilford Press.

14. Hedeker, D., Mermelstein, R. J., \& Demirtas, H. (2007). Analysis of binary outcomes with missing data: missing $=$ smoking, last observation carried forward, and a little multiple imputation. Addiction, 102, 1564-1573. doi:10.1111/j.1360-0443.2007.01946.x.

15. Abroms, L. C., Windsor, R., \& Simons-Morton, B. (2008). Getting young adults to quit smoking: A formative evaluation of the X-Pack Program. Nicotine \& Tobacco Research, 10, 27-33. doi:10.1080/14622200701767852.

16. Zanis, D. A., Hollm, R. E., Derr, D., Ibrahim, J. K., Collins, B. N., Coviello, D.,\& Melochick, J. R. (2011). Comparing intervention srategies among rural, low SES,young adult tobacco users. American Journal of Health Behavior, 35, 240-247. Retrieved from http://search.ebscohost.com/login.aspx?direct=true $\& \mathrm{db}=\mathrm{a}$ 9h\&AN=59513294\&site=ehost-live.

17. Vidrine, J. I., Shete, S., Cao, Y., Greisinger, A., Harmonson, P., Sharp, B., ... Wetter, D. W. (2013). Ask-Advise-Connect: A new approach to smoking treatment delivery in health care settings. JAMA Internal Medicine, 173, 458-464. doi:10.1001/ jamainternmed.2013.3751.

18. Vidrine, J. I., Shete, S., Li, Y., Cao, Y., Alford, M. H., GalindoTalton, M., ... Wetter, D. W. (2013). The Ask-Advise-Connect approach for smokers in a safety net healthcare system: A grouprandomized trial. American Journal of Preventive Medicine, 45, 737-741. doi:10.1016/j.amepre.2013.07.011.

19. Levinson, A. H. (2017). Where the U.S. tobacco epidemic still rages: Most remaining smokers have lower socioeconomic status. Journal of Health Care for the Poor \& Underserved, 28, 100-107. doi:10.1353/hpu.2017.0012.

20. Koh, H. (2016). Place matters for tobacco control. JAMA: The Journal of the American Medical Association, 316, 700-701. doi:10.1001/jama.2016.10537.

21. Connor Gorber, S., Schofield-Hurwitz, S., Hardt, J., Levasseur, G., \& Tremblay, M. (2009). The accuracy of self-reported smoking: A systematic review of the relationship between self-reported and cotinine-assessed smoking status. Nicotine \& Tobacco Research, 11, 12-24. doi:10.1093/ntr/ntn010.

22. D'Silva, J., Schillo, B. A., Sandman, N. R., Leonard, T. L., \& Boyle, R. G. (2011). Evaluation of a tailored approach for tobacco dependence treatment for American Indians. American Journal of Health Promotion, 25, S66-S69. doi:10.4278/ ajhp.100611-QUAN-180.

23. Munoz, R. F., Lenert, L. L., Delucchi, K., Stoddard, J., Perez, J. E., Penilla, C., \& Perez-Stable, E. J. (2006). Toward evidencebased Internet interventions: A Spanish/English Web site for international smoking cessation trials. Nicotine \& Tobacco Research, 8, 77-87. doi:10.1080/14622200500431940.

24. Thomas, J. L., Luo, X., Bengtson, J. E., Weber-Main, A. M., Lust, K., Ahluwalia, J. S., \& An, L. (2016). "Quit \& win” contests among college students. American Journal of Health Promotion, 30, 264-271. doi:10.1177/0890117116639560. 